\title{
Integrated ISM-Fuzzy MICMAC approach based factor analysis on the implementation of safety program in construction industry
}

\author{
Saber Ibrahima and Nejah Ben Mabrouk ${ }^{\text {a,b* }}$
}

\begin{abstract}
${ }^{a}$ Department of Management Information Systems and Producion Management,College of Business and Economics, Qassim University, P.O. Box: 6640, Buraidah 51452, Qassim, Saudi Arabia

${ }^{b}$ OLID Laboratory, Higher Institute of Industrial Management, University of Sfax, Road of Tunis km 10.5, Technopolis of Sfax - BP 1164, Sfax 3021, Tunisia

\section{H R O N I C L E}

Article history:

Received June 28, 2020

Received in revised format:

October 29, 2020

Accepted November 172020

Available online

November 17, 2020

Keywords:

Safety program

Fuzzy logic

Interpretive Structural Modeling

(ISM)

Fuzzy MICMAC

A B S T R A C T

The challenge of improving construction safety performance is observed in many countries. Safety is considered by practitioners and researchers as an important topic in construction industry sites. Despite the findings of implementing safety programs, it is revealed that accidents and injuries are not perfectly reduced in construction projects. In the literature, authors tried to establish several frameworks and proposed methods to reach this objective by identifying the key factors affecting safety performance. The aim of this study is to present critical factors used in the implementation of safety programs and to explore their relationships using Interpretive Structural Modeling (ISM). Then, via ISM technique, the overall structure among factors was revealed. By using the Fuzzy MICMAC analysis, the factors were classified into four groups based on their driving power and dependence power. The results showed that "Safety Training" and "Management Commitment" have the most important impact on safety programs, but also it is very important to study the interactions among factors at different stages. This analysis offers key resources for practitioners and decision makers by analyzing the relationships between factors and its driving or dependence strength. These results shed lights on the effective development of measures to facilitate the implementation of safety programs in the construction sector.
\end{abstract}

\section{Introduction}

In the 1980s, the European Union introduced the safety management system to encourage safety and health improvements in the workplace (Leveson, 2015). Several researchers agreed with the fact that construction belongs to the family of the most dangerous industries such as Fang and Wu (2013), Wanberg et al. (2013) and Al-Humaidi and Tan (2010). In an urban context, the accidents issued from construction industry are due to the growth and the complexity of the construction projects such as working at height, working in restrained spaces, underground construction activities, exposure to live cables, poor housekeeping and ergonomics which is in line with modernizing cities and high demand for offices and services. According to Yiu and Chan (2018), accidents on construction sites represented about $20 \%$ of industrial accidents in Japan, South Korea, Singapore and Hong Kong, during the period between 1995 and 2005. Furthermore, the National Safety Council reports declared that more than 10,000 people have died at construction locations in the US in the last decades. Therefore, safety management system for building and construction has been introduced by practitioners and researchers in many countries. Suraji et al. (2001) stated that the importance should be focused on the way with which project management can help the improvement of the location safety. Now, it is advised to integrate safety management into project management. Flin et al. * Corresponding author.

E-mail address: mabrouknejah@gmail.com (N. B. Mabrouk)

(C) 2021 by the authors; licensee Growing Science, Canada. doi: $10.5267 /$ j.dsl.2020.11.005 
(2000) declared that considering construction safety management is related to the consideration of safety culture and safety climate which represent two important aspects in construction projects. According to Pheng and Shiua (2000), reaching the objective of good quality of buildings is not enough; the industry should focus also on supporting safe working environments at construction sites. Safety program is considered as a practical approach that improves safety at building tasks (Tam et al., 2004). Thus, the rate of injuries and accidents will decrease significantly with the assistance of proper building practices and a secure working environment for workers (Haadir \& Panuwatwanich, 2011). For this reason, the key of achieving better operational results is related to recognizing critical factors that affect safety programs in construction projects.

The aim of this paper is to identify the important factors affecting construction safety performance and extract the relationship measures between them. Thus, providing a framework for construction safety program is necessary and very useful for practitioners and experts. In the next section, we will present a summary of findings of authors related to factors selection and the important methods associated with construction safety management. Then, the proposed research methodology is presented. At this stage, we described our proposed model based on ISM approach and we improved it by applying a fuzzy MICMAC analysis. Furthermore, the obtained results are discussed and explained. Finally, some closing comments are provided and recommendations are made for potential research topics.

\section{Literature review and factors affecting construction safety performance}

Top managers have as targets of every organization to increase the level of safety at construction places and to obtain the best safety records. For this reason, the key factors that affect the safety efficiency of construction projects should be first identified and then regulated to keep their enhanced competitive situation (Ismail et al., 2012). A large number of recent studies have investigated the identification of factors that affect construction safety. Most organizations have implemented credible safety plans and policies which follow industry health and safety procedures. But, critical factors should be well studied and structured by defining the causal relationship between them to establish safety procedures because occurrences and injuries at construction places are issued generally from a direct result. In his study, Jannadi (1996) gave to each critical factor a weight according to its importance and identified six factors which are maintaining the conditions of a safe work, safety training, main contractor control, workers and supervisors training, keeping a close observation for employees and responsibility assignment to all levels of staff. Besides, Sawacha et al. (1999) stated that the best important factors are management discuss on safety, safety equipment, providing for safety flyers and brochures, skilled safety representative and safety environment. Fang et al. (2004) listed five factors affecting safety management performance at construction locations in China. These factors are those related to workers, team management, safety training, managers, and controller. In their study, Tam et al. (2004) recorded the following factors: lack of training, manager's safety awareness, top management awareness, hesitancy to input resources for safety and irresponsible operations. In their model evaluating the safety management performance of construction projects, $\mathrm{Li}$ and $\mathrm{Li}$ (2009) found that the key factors influencing the performance of the safety management are essentially equipment and material management, safety management organization, safety personal and safety management measures. Omran et al. (2010) stated that the factors that should be considered in Malaysian construction projects are communication, continuous participation of employee, safety committee/safety officer, clear and realistic goals and resource allocation. Jitwasinkul and Hadikusuno (2011) identified seven factors of Thailand construction projects, namely: communication, manager commitment, organization learning, reward system, leadership, empowerment and culture. Hasan and Jha (2013) determined six factors of safety performance in Indian construction projects which are: consideration of risky situations safety, specific works and safety equipment, proper labor training, incentive sharing process and the perfect procedure of incentive/penalty.

In literature, it is shown that management commitment is considered as the most dominant factor that affects construction safety. It consists of respecting two essential instructions: implementing organizational safety policies and assigning safety responsibilities at all levels. It is a critical component of safety climate, which refers to employees' observations of the degree to which their top managers value and support safe working. This factor contains many sub factors that must be indicated and classified according to their weights. Jannadi (1996), Fang et al. (2004) introduced the relation between top management support and good labor. Also, Jannadi (1996) stated that organizations may allocate safety responsibilities to all workers in order to ensure construction safety. Teo et al. (2005) presented the harmony of a relevant legislation and the company safety policies and the safety management systems. Another sub-factor has been mentioned in the work of Hinze and Rebound (1988) which is the full-time safety officers and project safety staff, also particular occupation safety tours and inspections. Furthermore, Jannadi (1996) and Lee and Halpin (2003) suggested that monitoring site safety and the provision of a safe environment are factors linked to the implementation of safety systems at construction sites. Al-Bsheish et al. (2017) established a framework to study the causal relations between perceived management commitment to safety, respect, physical empowerment and safety performance.

Safety training is another important factor affecting construction projects safety projects. Law et al. (2006) defined safety training as the transmission of knowledge related to safety and how this knowledge can arrange an appropriate and safe environment of working. Thus, safety training can improve some managerial components within the organization. Several authors treated this factor in their studies such as the works of Manu et al. (2017), Jafari et al. (2015) and Namian, et al. (2016). According to Barbaranelli et al. (2015), the safety outcomes are function of planned health and safety programs for new staffs, orientation for new staff, advances in occupational health and safety systems and counseling and progression 
planning programs. Moreover, many researchers such as Brahm and Singer (2013) and Namian et al. (2016) affirmed that organizations having active safety training programs reported low accidents and injuries rates.

Safety culture has been studied intensely by researchers. In literature, it is defined as a set of interconnected principles, norms and behavioral dispositions among employees and top management. it has a real impact on the construction safety projects. Cooper (2000) considered safety culture as an aspect that belongs to organizational culture, which affects staff attitudes and comportments in relation to the safety performance of any organization.

Safety rewards and incentives are extensively used in organizations to promote employees in order to contribute positively in safety management process. In their work, Gangwar and Goodrum (2005) studied the effectiveness of safety incentives in US construction firms and they showed that incentives are effective at improving many of the safety performance metrics. Also, Fang et al. (2004) studied safety management performance on construction sites in China by the use of a multifactor linear regression. in their study, they showed that safety incentives are considered as one of the key factors affecting safety on construction projects. Furthermore, Hinze et al. (2013) have shown that safety performance is improved as the number of safety procedures increases and they stated that safety incentives is one of the best factors that reduces worker injuries.

Pre-task safety management plan involves the different features that enumerates general aspects of a task. this plan might help employees to recognize hazards before the accomplishment of each task. Feng (2013) indicated that pre-task analysis helps workers to identify the associated hazards and suggests recommendations for controlling them. furthermore, the Construction Industry Institute reported that pre-task project planning is one of the five important factors leading up to zero accidents.

Project nature is an important factor for safety performance as several authors confirmed (Charehzehi and Alankoob, 2013). It includes the organization of many aspects related to the construction project such as the size, the cost, the application of new technology, the type of owner, the number of subcontractors, the complexity of the design and the duration. Besides, understanding how to manage project complexity has a significant importance for achieving successful projects.

Safety knowledge and skills encloses the preparation of a solid knowledge process and improving and assessing of employees skills. This factor can be a moderator between safety environment and safety performance (Li et al., 2019). In this context, Zhang et al. (2015) proposed an ontology of construction-safety knowledge to enable more effective safety knowledge inquiries.

Staffing for safety is widely used by organizations leaders because of its importance to assure the improvement of safety projects. Several authors have stated that this factor is one of the main factors influencing safety performance such as the studies of Khan et al. (2015) and Aksorn and Hadikusumo (2008).

Based on the literature survey, developed studies on construction projects have lack of interpreting the correlations between sub-factors. However, the elements causing safety performance should be well studied for better classification. The present study aims to recognize the factors and the sub-factors that affect construction safety performance in the Tunisian context. A relevant overview of literature safety studies was offered in order to recognize the factors and their features and then to classify them according to their relationships and importance.

\section{Solution methodology and model development}

For this study, a hybrid research approach comprising two stages (Fig.1) was implemented to achieve the goals of this research. In the first step, a systematic literature review was performed to determine the factors influencing the implementation of construction safety program. This step is accompanied by a review of the questionnaire to elicit experts' opinions of the contextual relationships between these variables. At this stage, the adjacency and the reachability matrices are built using ISM methodology and the hierarchical structure is developed. During the second stage, these variables were categorized using the Fuzzy MICMAC analysis according to driving power and dependency power. Thus, the dominant contributory factors are determined.

ISM-MICMAC approach has efficaciously applied in numerous real-life applications like, evolving interrelationship among the variables affecting supply chain (Majumdar and Sinha, 2019; Ben Mabrouk, 2020), analyzing interactions among the barriers of green supply chain management (Jayant and Azhar, 2014), factors of occupant behavior in pre-evacuation time (Liu et al., 2020), exploring the interactions among factors affecting lean six sigma implementation (Ben Mabrouk et al., 2020; Kaswan and Rathi, 2019), extracting the effective factors on unsafe acts of workers in industries (Shakerian et al., 2019), and modeling the drivers of buyer-supplier relationships (Thakkar et al., 2007; Ben Mabrouk, 2020a).

\subsection{ISM approach}

\subsubsection{Development of SSIM}

The SSIM is formulated from the interrelationships among the 13 selected factors illustrated in Table 1. In this study, we arranged meetings with individual expert and we kept in mind contextual relationships for each critical factor during the 
implementation. The analysis of the relation between any two factors $\mathrm{i}$ and $\mathrm{j}$ is directed. Four symbols were used to show the direction of relationship between factors $(\mathrm{i}, \mathrm{j})$ : $\mathrm{F}$ : forward relationship from $\mathrm{i}$ to $\mathrm{j}(F=i \rightarrow j)$; R: reverse link from $\mathrm{j}$ to $\mathrm{i}$ $(R=j \rightarrow i)$; FR: Dual directional relationship between $\mathrm{i}$ and $\mathrm{j}(F R=j \leftrightarrow i)$ and $\mathrm{X}$ : factors $\mathrm{i}$ and $\mathrm{j}$ are unrelated $(X=i \otimes j)$.

First stage: ISM approach

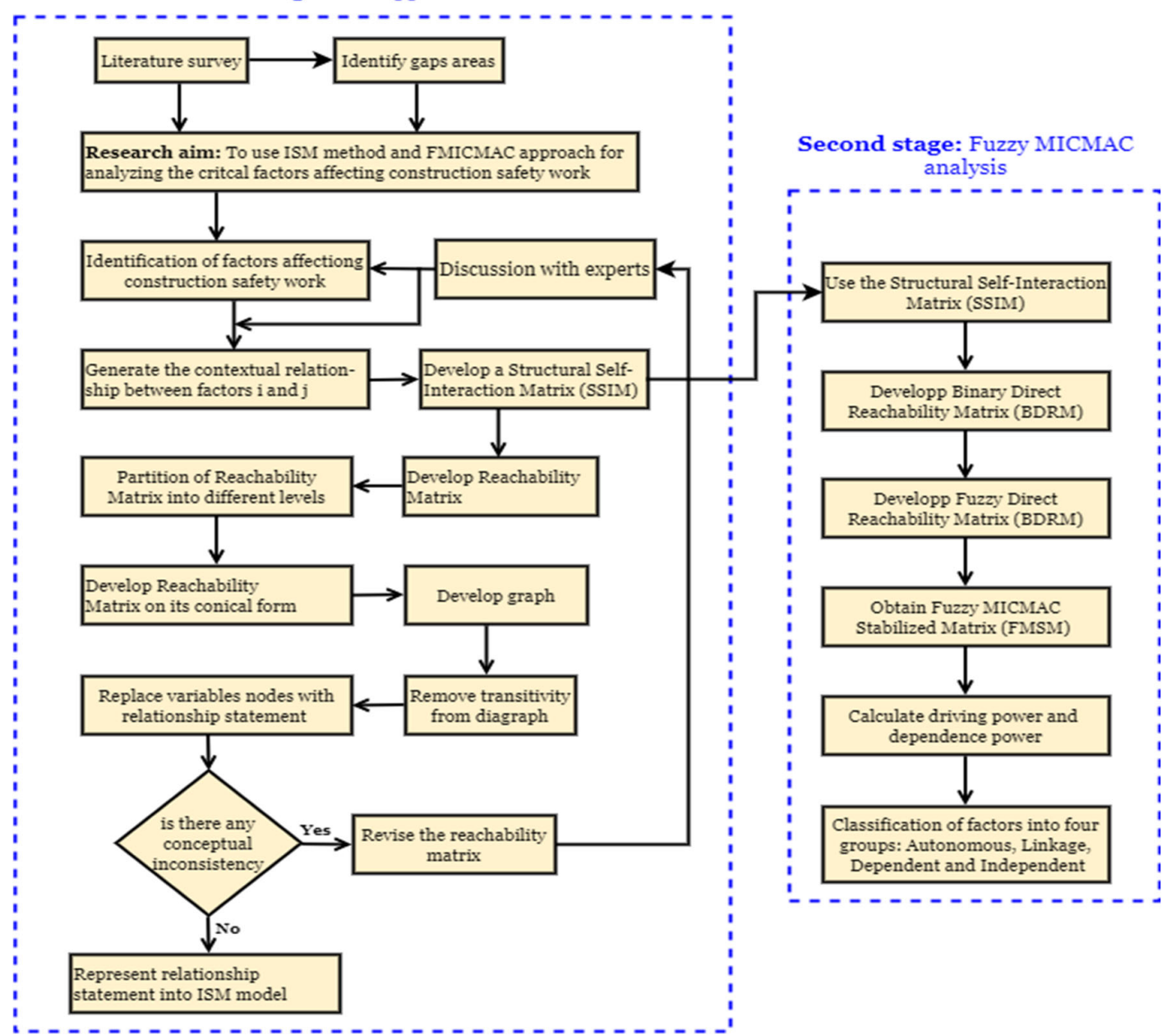

Fig.1. Flowchart of research approach: Integrated ISM-Fuzzy MICMAC

\subsubsection{Development of initial Reachability Matrix (IRM)}

The initial matrix of reachability (Table 2) is achieved by modifying each SSIM entry into 1s and 0s respecting the following transformation rules. If the cell $(i, j)$ in SSIM is F, then in MRI, cell $(i, j)$ becomes 1 and cell $(j, i)$ becomes 0 . In case that the cell $(i, j)$ in SSIM is R, then, in IRM, the entry $(i, j)$ becomes equal to 0 and the entry $(j, i)$ becomes equal to 1 . In case that the cell $(i, j)$ in SSIM is FR, then, in the IRM, both entries (i, j) and (j, i) become equal to 1 . Finally, If the entry (i, j) in the SSIM is X, then, in the IRM, both entries $(i, j)$ and $(j, i)$ become equal to 0 .

Table 1

Structural self-interaction matrix (SSIM)

\begin{tabular}{|c|c|c|c|c|c|c|c|c|c|c|c|c|c|c|}
\hline $\mathbf{X i}$ & Factors & $\mathrm{X} 1$ & $\mathrm{X} 2$ & $\mathrm{X} 3$ & $\mathrm{X} 4$ & $\mathrm{X} 5$ & $\mathrm{X} 6$ & $\mathrm{X} 7$ & $\mathrm{X} 8$ & $\mathrm{X} 9$ & $\mathrm{X} 10$ & $\mathrm{X} 11$ & $\mathrm{X} 12$ & $\mathrm{X} 13$ \\
\hline $\mathrm{X} 1$ & Management commitment (MC) & $F R$ & $F$ & $F$ & $X$ & $X$ & $F$ & $F$ & $F$ & $X$ & $F$ & $F$ & $F$ & $F$ \\
\hline $\mathrm{X} 2$ & Communication $(\mathrm{C})$ & & $F R$ & $R$ & $F$ & $X$ & $F$ & $R$ & $F$ & $X$ & $F$ & $X$ & $F$ & $F$ \\
\hline $\mathrm{X} 3$ & Safety training (ST) & & & $F R$ & $F$ & $X$ & $F$ & $F$ & $X$ & $X$ & $F$ & $R$ & $F$ & $F$ \\
\hline $\mathrm{X} 4$ & Safety rewards/incentives (SRI) & & & & $F R$ & $X$ & $X$ & $R$ & $R$ & $X$ & $F$ & $X$ & $F$ & $X$ \\
\hline $\mathrm{X} 5$ & Project nature $(\mathrm{PN})$ & & & & & $F R$ & $F$ & $X$ & $F$ & $F$ & $F$ & $F$ & $F$ & $X$ \\
\hline X6 & Pre-task Safety measures (PSM) & & & & & & $F R$ & $R$ & $R$ & $F$ & $X$ & $F R$ & $R$ & $R$ \\
\hline $\mathrm{X} 7$ & Safety culture (SC) & & & & & & & $F R$ & $F$ & $F$ & $F$ & $X$ & $F R$ & $F$ \\
\hline $\mathrm{X} 8$ & Safety Plan (SP) & & & & & & & & $F R$ & $F$ & $F$ & $F$ & $R$ & $X$ \\
\hline X9 & Operating environment (OE) & & & & & & & & & $F R$ & $F$ & $X$ & $X$ & $R$ \\
\hline $\mathrm{X} 10$ & Worker involvement (WI) & & & & & & & & & & $F R$ & $R$ & $R$ & $R$ \\
\hline $\mathrm{X} 11$ & Safety resource (SR) & & & & & & & & & & & $F R$ & $R$ & $R$ \\
\hline $\mathrm{X} 12$ & Staffing for safety (SFS) & & & & & & & & & & & & $F R$ & $F$ \\
\hline $\mathrm{X} 13$ & Safety knowledge and skills (SKS) & & & & & & & & & & & & & $F R$ \\
\hline
\end{tabular}


Table 2

Initial reachability matrix (IRM)

\begin{tabular}{|c|c|c|c|c|c|c|c|c|c|c|c|c|c|}
\hline $\mathbf{X i}$ & $\mathrm{X} 1$ & $\mathrm{X} 2$ & X3 & $\mathrm{X} 4$ & X5 & X6 & X7 & $\mathrm{X} 8$ & X9 & $\mathrm{X} 10$ & $\mathrm{X} 11$ & $\mathrm{X} 12$ & X13 \\
\hline $\mathrm{X} 1$ & 1 & 1 & 1 & 0 & 0 & 1 & 1 & 1 & 0 & 1 & 1 & 1 & 1 \\
\hline $\mathrm{X} 2$ & 0 & 1 & 0 & 1 & 0 & 1 & 0 & 1 & 0 & 1 & 0 & 1 & 1 \\
\hline X3 & 0 & 1 & 1 & 1 & 0 & 1 & 1 & 0 & 0 & 1 & 0 & 1 & 1 \\
\hline $\mathrm{X} 4$ & 0 & 0 & 0 & 1 & 0 & 0 & 0 & 0 & 0 & 1 & 0 & 1 & 0 \\
\hline X5 & 0 & 0 & 0 & 0 & 1 & 1 & 0 & 1 & 1 & 1 & 1 & 1 & 0 \\
\hline X6 & 0 & 0 & 0 & 0 & 0 & 1 & 0 & 0 & 1 & 0 & 1 & 0 & 0 \\
\hline X7 & 0 & 1 & 0 & 1 & 0 & 1 & 1 & 1 & 1 & 1 & 0 & 1 & 1 \\
\hline X8 & 0 & 0 & 0 & 1 & 0 & 1 & 0 & 1 & 1 & 1 & 1 & 0 & 0 \\
\hline X9 & 0 & 0 & 0 & 0 & 0 & 0 & 0 & 0 & 1 & 1 & 0 & 0 & 0 \\
\hline $\mathrm{X} 10$ & 0 & 0 & 0 & 0 & 0 & 0 & 0 & 0 & 0 & 1 & 0 & 0 & 0 \\
\hline $\mathrm{X} 11$ & 0 & 0 & 1 & 0 & 0 & 1 & 0 & 0 & 0 & 1 & 1 & 0 & 0 \\
\hline $\mathrm{X} 12$ & 0 & 0 & 0 & 0 & 0 & 1 & 1 & 1 & 0 & 1 & 1 & 1 & 1 \\
\hline $\mathrm{X} 13$ & 0 & 0 & 0 & 0 & 0 & 1 & 0 & 0 & 1 & 1 & 1 & 0 & 1 \\
\hline
\end{tabular}

\subsubsection{Development of Modified Reachability Matrix (MRM)}

The final reachability matrix was made respecting the transitivity principle which is based on the following rules: if variable $x 1$ is connected to $x 2$ and variable $x 2$ is connected to variable $x 3$, then variable $x 1$ is necessarily connected to variable $x 3$ (Kumar et al., 2015). In addition, if variable $x 1$ is connected to variable $x 2$ and variable $x 2$ is connected to variable $x 4$, then variable $x 1$ is essentially related to variable $x 4$ (Fig.2).

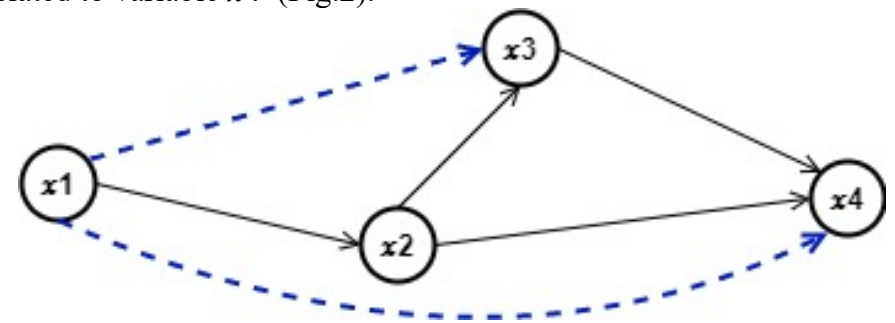

Fig. 2. Transitivity rules

The following step was to apply the described instructions and to consider the presence of transitivity by experts in order to construct the MRM as shown in Table 3. The entry 1 means that the factor in row influences the factor in column. The entry 0 means that the factor in row does not influence the factor in column. The entries on gray indicate transitivity links.

Table 3

Modified reachability matrix (MRM)

\begin{tabular}{|c|c|c|c|c|c|c|c|c|c|c|c|c|c|}
\hline $\mathbf{X i}$ & $\mathrm{X} 1$ & $\mathrm{X} 2$ & X3 & $\mathrm{X} 4$ & X5 & X6 & $\mathrm{X7}$ & $\mathrm{X} 8$ & X9 & X10 & X11 & X12 & X13 \\
\hline X1 & 1 & 1 & 1 & 1 & 0 & 1 & 1 & 1 & 1 & 1 & 1 & 1 & 1 \\
\hline X2 & 0 & 1 & 0 & 1 & 0 & 1 & 1 & 1 & 1 & 1 & 1 & 1 & 1 \\
\hline $\mathbf{X 3}$ & 0 & 1 & 1 & 1 & 0 & 1 & 1 & 1 & 1 & 1 & 1 & 1 & 1 \\
\hline X4 & 0 & 0 & 0 & 1 & 0 & 1 & 1 & 1 & 0 & 1 & 1 & 1 & 1 \\
\hline X5 & 0 & 0 & 1 & 1 & 1 & 1 & 1 & 1 & 1 & 1 & 1 & 1 & 1 \\
\hline X6 & 0 & 0 & 1 & 0 & 0 & 1 & 0 & 0 & 1 & 1 & 1 & 0 & 0 \\
\hline $\mathbf{X} 7$ & 0 & 1 & 0 & 1 & 0 & 1 & 1 & 1 & 1 & 1 & 1 & 1 & 1 \\
\hline X8 & 0 & 0 & 1 & 1 & 0 & 1 & 0 & 1 & 1 & 1 & 1 & 1 & 0 \\
\hline X9 & 0 & 0 & 0 & 0 & 0 & 0 & 0 & 0 & 1 & 1 & 0 & 0 & 0 \\
\hline X10 & 0 & 0 & 0 & 0 & 0 & 0 & 0 & 0 & 0 & 1 & 0 & 0 & 0 \\
\hline X11 & 0 & 1 & 1 & 1 & 0 & 1 & 1 & 0 & 1 & 1 & 1 & 1 & 1 \\
\hline X12 & 0 & 1 & 1 & 1 & 0 & 1 & 1 & 1 & 1 & 1 & 1 & 1 & 1 \\
\hline X13 & 0 & 0 & 1 & 0 & 0 & 1 & 0 & 0 & 1 & 1 & 1 & 0 & 1 \\
\hline
\end{tabular}

\subsubsection{Level partition}

The reachability matrix obtained in the previous step has been divided into different levels. The reachability and the antecedent set for each factor were established from the modified reachability matrix (Table 3) (Warfield, 1974). Then, the intersection between the reachability and the antecedent sets is extracted for all factors. Factors for which reachability and intersection are identical occupy the highest level (Level 1) of the ISM hierarchy (Table 4). Elements that belong to level 1 
of the hierarchy are influenced or driven by other elements. Level 2 (Table 5) is formed by removing the elements occupying level 1 as well as from the reachability, antecedent and intersection sets of the elements which do not occupy level 1 . Then, the process is repeated to find the elements belonging to the next level until all elements have been taken into account in the ISM structure. Level partition obtained after the final iteration is presented in Table 6.

Table 4

Level partition-iteration 1

\begin{tabular}{|c|c|c|c|c|}
\hline $\mathbf{X i}$ & RS(Xi) & $\mathbf{A S}(\mathbf{X i})$ & $\mathbf{R S}(\mathrm{Xi}) \cap \mathbf{A S}(\mathrm{Xi})$ & level \\
\hline $\mathrm{X} 1$ & $\begin{array}{l}\text { X1 X2 X3 X4 X6 X7 X8 X9 X10 X11 X12 } \\
\text { X13 }\end{array}$ & $\mathrm{X} 1$ & $\mathrm{X} 1$ & \\
\hline $\mathrm{X} 2$ & X2 X4 X6 X7 X8 X9 X10 X11 X12 X13 & X1 X2 X3 X7 X11 X12 & X2 X7 X11 X12 & \\
\hline $\mathrm{X} 3$ & X2 X3 X4 X6 X7 X8 X9 X10 X 11 X 12 X13 & X1 X3 X5 X6 X8 X11 X12 X13 & X3 X6 X8 X11 X12 X13 & \\
\hline $\mathrm{X} 4$ & X4 X6 X7 X8 X10 X11 X12 X13 & X1 X2 X3 X4 X5 X7 X8 X11 X12 & X4 X7 X8 X11 X12 & \\
\hline $\mathrm{X} 5$ & X3 X4 X5 X6 X7 X8 X9 X10 X 11 X 12 X13 & $\mathrm{X} 5$ & X5 & \\
\hline X6 & X3 X6 X9 X10 X11 & X1 X 2 X 3 X 4 X 56 X7 X8 X 11 X 12 X13 & X3 X6 X11 & \\
\hline $\mathrm{X} 7$ & X2 X4 X6 X7 X8 X9 X10 X11 X12 X13 & X1 X2 X3 X4 X5 X7 X11 X12 & X2 X4 X7 X11 X12 & \\
\hline $\mathrm{X} 8$ & X3 X4 X6 X8 X9 X10 X11 X12 & X1 X2 X3 X4 X5 X7 X8 X12 & X3 X4 X8 X12 & \\
\hline X9 & X9 X10 & X1 X2 X3 X5 X6 X7 X8 X9 X11 X12 X13 & X9 & \\
\hline $\mathrm{X} 10$ & $\mathrm{X} 10$ & $\begin{array}{l}\text { X1 X2 X3 X4 X5 X6 X7 X8 X9 X10 X11 X12 } \\
\text { X13 }\end{array}$ & $\mathrm{X} 10$ & L1 \\
\hline $\mathrm{X} 11$ & X2 X3 X4 X6 X7 X9 X10 X11 X12 X13 & X1 X2 X3 X4 X5 X6 X7 X8 X11 X12 X13 & $\begin{array}{l}\text { X2 X3 X4 X6 X7 X11 X12 } \\
\text { X13 }\end{array}$ & \\
\hline $\mathrm{X} 12$ & X2 X3 X4 X6 X7 X8 X9 X10 X11 X12 X13 & X1 X2 X3 X4 X5 X7 X8 X11 X12 & X2 X3 X4 X7 X8 X11 X12 & \\
\hline X13 & X3 X6 X9 X10 X11 X13 & X1 X2 X3 X4 X5 X7 X11 X12 X13 & X3 X11 X13 & \\
\hline
\end{tabular}

Table 5

Level partition-iteration 2

\begin{tabular}{|c|c|c|c|c|}
\hline $\mathbf{X i}$ & RS(Xi) & $\mathbf{A S}(\mathbf{X i})$ & $\mathbf{R S}(\mathbf{X i}) \cap \mathbf{A S}(\mathbf{X i})$ & level \\
\hline $\mathrm{X} 1$ & $\begin{array}{l}\text { X1 X2 X3 X4 X6 X7 X8 X9 X11 } \\
\text { X12 X13 }\end{array}$ & $\mathrm{X} 1$ & $\mathrm{X} 1$ & \\
\hline $\mathrm{X} 2$ & X2 X4 X6 X7 X8 X9 X11 X12 X13 & X1 X2 X3 X7 X11 X12 & X2 X7 X11 X12 & \\
\hline $\mathrm{X} 3$ & $\begin{array}{l}\text { X2 X3 X4 X6 X7 X8 X9 X11 X12 } \\
\text { X13 }\end{array}$ & X1 X3 X5 X6 X8 X11 X12 X13 & X3 X6 X8 X11 X12 X13 & \\
\hline $\mathrm{X} 4$ & X4 X6 X7 X8 X11 X12 X13 & X1 X2 X3 X4 X5 X7 X8 X11 X12 & X4 X7 X8 X11 X12 & \\
\hline $\mathrm{X} 5$ & $\begin{array}{l}\text { X3 X4 X5 X6 X7 X8 X9 X11 X12 } \\
\text { X13 }\end{array}$ & $\mathrm{X} 5$ & $\mathrm{X} 5$ & \\
\hline $\mathrm{X} 6$ & X3 X6 X9 X11 & Х1 X2 X3 X4 X5 X6 X7 X8 X11 X12 X13 & X3 X6 X11 & \\
\hline $\mathrm{X} 7$ & X2 X4 X6 X7 X8 X9 X11 X12 X13 & X1 X2 X3 X4 X5 X7 X11 X12 & X2 X4 X7 X11 X12 & \\
\hline $\mathrm{X} 8$ & X3 X4 X6 X8 X9 X11 X12 & X1 X2 X3 X4 X5 X7 X8 X12 & X3 X4 X8 X12 & \\
\hline X9 & X9 & Х1 X2 X3 X 566 X7 X8 X9 X 11 X 12 X 13 & X9 & L2 \\
\hline $\mathrm{X} 11$ & X2 X3 X4 X6 X7 X9 X11 X12 X13 & X1 X2 X3 X4 X5 X6 X7 X8 X11 X12 X13 & X2 X3 X4 X6 X7 X11 X12 X13 & \\
\hline $\mathrm{X} 12$ & $\begin{array}{l}\text { X2 X3 X4 X6 X7 X8 X9 X11 X12 } \\
\text { X13 }\end{array}$ & X1 X2 X3 X4 X5 X7 X8 X11 X12 & X2 X3 X4 X7 X8 X11 X12 & \\
\hline X 13 & X3 X6 X9 X11 X13 & X1 X2 X3 X4 X5 X7 X11 X12 X13 & $\mathrm{X} 3 \mathrm{X} 11 \mathrm{X} 13$ & \\
\hline
\end{tabular}

Table 6

Level partition after final iteration.

\begin{tabular}{|c|c|c|c|c|}
\hline $\mathbf{X i}$ & $\mathbf{R S}(\mathrm{Xi})$ & $\operatorname{AS}(\mathbf{X i})$ & $\mathbf{R S}(\mathbf{X i}) \cap \mathbf{A S}(\mathbf{X i})$ & level \\
\hline $\mathrm{X} 1$ & A1 A2 A3 & A1 & A1 & L7 \\
\hline $\mathrm{X} 2$ & A2 & A1 A2 A3 & A2 & L6 \\
\hline $\mathrm{X} 3$ & $\mathrm{X} 2 \mathrm{X} 3$ & $\mathrm{X} 1 \mathrm{X} 3$ & $\mathrm{X} 3$ & L7 \\
\hline $\mathrm{X} 4$ & X4 X7 X12 & X1 X2 X3 X4 X7 X12 & X4 X7 X12 & L5 \\
\hline $\mathrm{X} 5$ & X5 & X5 & X5 & L6 \\
\hline X6 & X3 X6 X11 & X1 X2 X3 X4 X5 X6 X7 X8 X11 X12 X13 & X3 X6 X11 & L3 \\
\hline $\mathrm{X} 7$ & $\mathrm{X} 2 \mathrm{X} 4 \mathrm{X} 7 \mathrm{X} 12$ & X1 X2 X3 X4 X5 X7 X12 & $\mathrm{X} 2 \mathrm{X} 4 \mathrm{X} 7 \mathrm{X} 12$ & L5 \\
\hline $\mathrm{X} 8$ & A4 A8 A12 & A1 A2 A3 A4 A5 A7 A8 A12 & A4 A8 A12 & L4 \\
\hline X9 & X9 & X1 X2 X3 X5 X6 X7 X8 X9 X11 X12 X13 & X9 & $\mathbf{L 2}$ \\
\hline $\mathrm{X} 10$ & $\mathrm{X} 10$ & X1 X2 X3 X4 X5 X6 X7 X8 X9 X10 X11 X12 X13 & $\mathrm{X} 10$ & L1 \\
\hline $\mathrm{X} 11$ & X2 X3 X4 X6 X7 X11 X12 X13 & X1 X2 X3 X4 X5 X6 X7 X8 X11 X12 X13 & X2 X3 X4 X6 X7 X11 X12 X13 & $\mathbf{L 3}$ \\
\hline $\mathrm{X} 12$ & $\mathrm{X} 2 \mathrm{X} 4 \mathrm{X} 7 \mathrm{X} 12$ & X1 X2 X3 X4 X5 X7 X12 & X2 X4 X7 X12 & L5 \\
\hline $\mathrm{X} 13$ & $\mathrm{X} 13$ & X1 X2 X3 X4 X5 X7 X12 X13 & $\mathrm{X} 13$ & L4 \\
\hline
\end{tabular}

\subsubsection{ISM based modeling}

The final hierarchical structural model is created using the modified reachability matrix. Based on the results of the level partitions, in the initial diagram, the thirteen factors were placed to show the chain of influence. The relationship between factors $i$ and $j$ is denoted graphically by an arrow starting from $i$ to $j$. The initial diagram is created with transitivity, from which the indirect links can be removed to construct a final diagram. 


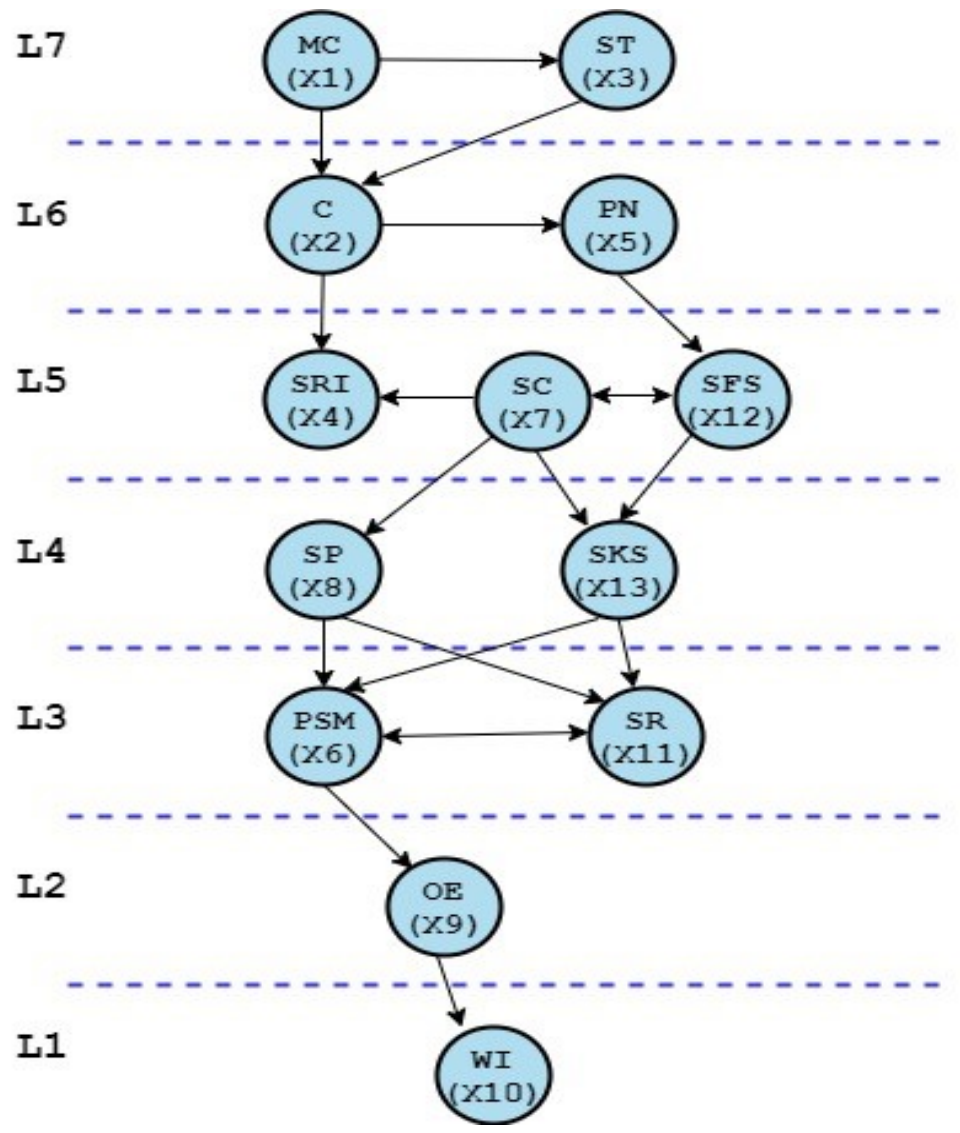

Fig.3. The hierarchical structure model of the influencing factors

\subsection{Fuzzy MICMAC analysis}

In the ISM based modeling, binary digits marked as 0 and 1 denoted the relationships between factors. If two factors are related, digit 1 is used, otherwise digit 0 will be used. It does not always reflect the actual state of the enabler relationship (Ben Mabrouk, 2021). Fuzzy set theory (FST) is further applied to address MICMAC analytical limitations and to improve the efficiency of ISM technique.

\subsubsection{Binary direct relationship matrix (BDRM)}

BDRM is provided by making zero diagonal entries and ignoring transitivity in the IRM of the of ISM-based modeling, as displayed in Table 7.

Table 7

Binary direct relationship matrix (BDRM)

\begin{tabular}{|c|c|c|c|c|c|c|c|c|c|c|c|c|c|}
\hline $\mathbf{X i}$ & $\mathrm{X} 1$ & $\mathrm{X} 2$ & X3 & $\mathrm{X} 4$ & X5 & X6 & X7 & X8 & X9 & $\mathrm{X} 10$ & X11 & X12 & X13 \\
\hline $\mathrm{X} 1$ & 0 & 1 & 1 & 0 & 0 & 1 & 1 & 1 & 0 & 1 & 1 & 1 & 1 \\
\hline $\mathrm{X} 2$ & 0 & 0 & 0 & 1 & 0 & 1 & 0 & 1 & 0 & 1 & 0 & 1 & 1 \\
\hline X3 & 0 & 1 & 0 & 1 & 0 & 1 & 1 & 0 & 0 & 1 & 0 & 1 & 1 \\
\hline $\mathrm{X} 4$ & 0 & 0 & 0 & 0 & 0 & 0 & 0 & 0 & 0 & 1 & 0 & 1 & 0 \\
\hline X5 & 0 & 0 & 0 & 0 & 0 & 1 & 0 & 1 & 1 & 1 & 1 & 1 & 0 \\
\hline X6 & 0 & 0 & 0 & 0 & 0 & 0 & 0 & 0 & 1 & 0 & 1 & 0 & 0 \\
\hline X7 & 0 & 1 & 0 & 1 & 0 & 1 & 0 & 1 & 1 & 1 & 0 & 1 & 1 \\
\hline X8 & 0 & 0 & 0 & 1 & 0 & 1 & 0 & 0 & 1 & 1 & 1 & 0 & 0 \\
\hline X9 & 0 & 0 & 0 & 0 & 0 & 0 & 0 & 0 & 0 & 1 & 0 & 0 & 0 \\
\hline X10 & 0 & 0 & 0 & 0 & 0 & 0 & 0 & 0 & 0 & 0 & 0 & 0 & 0 \\
\hline X11 & 0 & 0 & 1 & 0 & 0 & 1 & 0 & 0 & 0 & 1 & 0 & 0 & 0 \\
\hline $\mathrm{X} 12$ & 0 & 0 & 0 & 0 & 0 & 1 & 1 & 1 & 0 & 1 & 1 & 0 & 1 \\
\hline $\mathrm{X} 13$ & 0 & 0 & 0 & 0 & 0 & 1 & 0 & 0 & 1 & 1 & 1 & 0 & 0 \\
\hline
\end{tabular}

\subsubsection{Fuzzy direct relationship matrix (FDRM)}

Fuzzy set theory makes traditional MICMAC more sensitive. This fulfills this function by adding possibilities for additional input to the relationship between the factors in scales 0-1 (Qureshi et al., 2008). FDRM was created by placing zeros at the diagonal entries of the matrix and at the same time by ignoring transitivity rule of the IRM. The FDRM was achieved 
through the inclusion of all the expert opinions on a fuzzy reachability scale presented in Table 8. FDRM for key variables affecting construction safety performance is presented in Table 9.

\subsubsection{Fuzzy MICMAC stabilized matrix (FMSM)}

The established FDRM (Table 10) is used to construct a stable Fuzzy MICMAC matrix using the fuzzy multiplication principle. In addition, matrix multiplication is repeated until the driving and dependency power hierarchies are balanced (Jain and Raj 2015). The multiplication method was carried out using the fuzzy matrix multiplication principles. The result of the multiplication of the fuzzy matrix A by the fuzzy matrix B is the fuzzy matrix C that can be defined as follows:

$C=A^{*} B=\max _{k}\left[\min \left(a_{i k}, b_{k j}\right)\right.$, where $A=\left(a_{i k}\right)$ and $B=\left(b_{i k}\right)$ are two fuzzy matrices.

Table 8

Fuzzy reachability scale

\begin{tabular}{lccccccc}
\hline Possibility of reachability & No & Very low & low & Medium & High & Very high & Full \\
\hline value & 0 & 0.1 & 0.3 & 0.5 & 0.7 & 0.9 & 1 \\
\hline
\end{tabular}

Table 9

Fuzzy direct relationship matrix (FDRM)

\begin{tabular}{|c|c|c|c|c|c|c|c|c|c|c|c|c|c|}
\hline $\mathbf{X i}$ & $\mathrm{X} 1$ & $\mathrm{X} 2$ & X3 & $\mathrm{X} 4$ & X5 & X6 & $\mathrm{X7}$ & $\mathrm{X} 8$ & X9 & $\mathrm{X} 10$ & X11 & $\mathrm{X} 12$ & X13 \\
\hline $\mathrm{X} 1$ & 0 & 0.7 & 0.3 & 0 & 0 & 0.5 & 0.7 & 0.3 & 0 & 0.5 & 0.5 & 0.5 & 0.3 \\
\hline $\mathrm{X} 2$ & 0 & 0 & 0 & 0.5 & 0 & 0.3 & 0.3 & 0.7 & 0 & 0.3 & 0 & 0.3 & 0.5 \\
\hline X3 & 0 & 0.7 & 0 & 0.5 & 0 & 0.5 & 0.7 & 0 & 0 & 0.7 & 0 & 0.7 & 0.3 \\
\hline $\mathrm{X} 4$ & 0 & 0 & 0 & 0 & 0 & 0 & 0 & 0 & 0 & 0.7 & 0 & 0.5 & 0 \\
\hline X5 & 0 & 0 & 0 & 0 & 0 & 0.5 & 0 & 0.5 & 0.5 & 0.7 & 0.7 & 0.3 & 0 \\
\hline X6 & 0 & 0 & 0 & 0 & 0 & 0 & 0 & 0 & 0.5 & 0 & 0.5 & 0 & 0 \\
\hline X7 & 0.3 & 0.5 & 0 & 0.3 & 0 & 0.3 & 0 & 0.5 & 0.3 & 0.5 & 0 & 0.5 & 0.5 \\
\hline X8 & 0 & 0 & 0 & 0.5 & 0 & 0.7 & 0 & 0 & 0.7 & 0.5 & 0.3 & 0 & 0 \\
\hline X9 & 0 & 0 & 0 & 0 & 0 & 0 & 0 & 0 & 0 & 0.5 & 0 & 0 & 0 \\
\hline X10 & 0 & 0.1 & 0.3 & 0 & 0 & 0 & 0 & 0 & 0 & 0 & 0 & 0 & 0 \\
\hline X11 & 0 & 0 & 0.3 & 0 & 0 & 0.5 & 0 & 0 & 0 & 0.3 & 0 & 0 & 0 \\
\hline $\mathrm{X} 12$ & 0.1 & 0 & 0 & 0 & 0 & 0.7 & 0.5 & 0.3 & 0 & 0.5 & 0.3 & 0 & 0.3 \\
\hline $\mathrm{X} 13$ & 0 & 0 & 0 & 0 & 0 & 0.5 & 0 & 0 & 0.5 & 0.5 & 0.5 & 0 & 0 \\
\hline
\end{tabular}

Table 10

Fuzzy MICMAC stabilized matrix (FMSM)

\begin{tabular}{|c|c|c|c|c|c|c|c|c|c|c|c|c|c|}
\hline & $\mathrm{X} 1$ & $\mathrm{X} 2$ & X3 & $\mathrm{X} 4$ & $\mathrm{X} 5$ & X6 & $\mathrm{X} 7$ & $\mathrm{X} 8$ & X9 & $\mathrm{X} 10$ & X11 & $\mathrm{X} 12$ & $\mathrm{X} 13$ \\
\hline $\mathrm{X} 1$ & 0 & 0.9 & 0.7 & 0 & 0 & 0.5 & 0.9 & 0.7 & 0.3 & 0.7 & 0.7 & 0.7 & 0.5 \\
\hline $\mathrm{X} 2$ & 0 & 0 & 0 & 0.5 & 0.3 & 0.7 & 0.9 & 0.7 & 0.3 & 0.9 & 0 & 0.7 & 0.9 \\
\hline X3 & 0 & 0.9 & 0 & 0.7 & 0.5 & 0.5 & 0.7 & 0 & 0.5 & 0.9 & 0.5 & 0.9 & 0.9 \\
\hline $\mathrm{X} 4$ & 0 & 0.3 & 0 & 0 & 0 & 0 & 0 & 0 & 0 & 0.7 & 0 & 0.3 & 0 \\
\hline X5 & 0 & 0 & 0.3 & 0 & 0 & 0.5 & 0 & 0.1 & 0.5 & 0.5 & 0.7 & 0.3 & 0 \\
\hline X6 & 0 & 0 & 0 & 0 & 0 & 0 & 0 & 0.3 & 0.5 & 0 & 0.5 & 0 & 0 \\
\hline X7 & 0.3 & 0.7 & 0.7 & 0.7 & 0 & 0.7 & 0 & 0.5 & 0.7 & 0.3 & 0 & 0.9 & 0.7 \\
\hline X8 & 0 & 0.7 & 0 & 0.5 & 0.3 & 0.7 & 0 & 0 & 0.7 & 0.3 & 0.7 & 0 & 0 \\
\hline X9 & 0 & 0.3 & 0 & 0 & 0 & 0 & 0 & 0 & 0 & 0.5 & 0 & 0 & 0 \\
\hline X10 & 0 & 0.3 & 0.3 & 0.9 & 0 & 0 & 0.3 & 0 & 0 & 0 & 0 & 0 & 0.3 \\
\hline X11 & 0 & 0 & 0.1 & 0 & 0.5 & 0.9 & 0 & 0.3 & 0 & 0.3 & 0 & 0 & 0 \\
\hline X12 & 0.1 & 0.5 & 0 & 0.3 & 0 & 0.7 & 0.7 & 0.9 & 0 & 0.9 & 0.3 & 0 & 0.9 \\
\hline X13 & 0 & 0 & 0 & 0 & 0 & 0.5 & 0.7 & 0.5 & 0.5 & 0.7 & 0.5 & 0.3 & 0 \\
\hline
\end{tabular}

\subsubsection{Fuzzy MICMAC classification}

The thirteen factors have been categorized by converting the stabilized matrix, presented in Table 10, into a MICMAC diagram. Those factors are divided into four groups according to the driving and dependency powers (Faisal et al., 2006). The first group comprises the autonomous variables, which have less driving and less dependence power. These factors are relatively disconnected from the network and only have few powerful connections. It can be seen from Fig. 4 that there is one factor namely Project nature $(\mathrm{PN})$ which is autonomous factor. The second group portrays dependent variables with low influence power and high dependence power as shown in the bottom right portion of the graph (Fig. 4). There are five dependent factors: Worker Involvement (WI), Pre-task Safety Measures (PSM), Operating Environment (OE), Safety Rewards/Incentives (SRI) and Safety Resource (SR). The third group includes the connection factors that have a robust driving power and dependency. This group includes five variables: Communication (C), Staffing for safety (SFS), Safety Knowledge and Skills (SKS), Safety culture (SC) and Safety Plan (SP). The fourth group includes the driving factors that have a high driving and low dependence power. There are two driving factors which are Safety Training (ST) and Management Commitment (MC). These variables are the main driving factors and they are usually located at the bottom of the ISM hierarchy. 


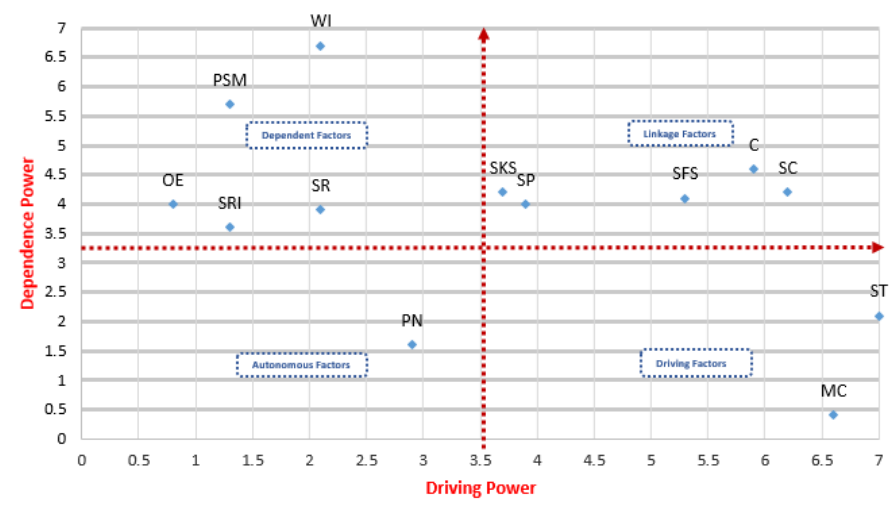

Fig. 4. Fuzzy MICMAC analysis.

\section{Results and discussion}

Construction industry is one of the risky industries and the statistics of injuries, illnesses and property damage in construction are higher than other industries. Safety performance issues have always been a major challenge in the construction industry. This work examined the key factors that can affect the performance of safety on construction locations. Thirteen critical factors of safety program implementation are identified through systematic literature review and further validated through experts' opinions. Furthermore, all factors were modeled through ISM and ranked based on their degree of influence by Fuzzy MICMAC analysis. The findings of the study were outlined in Fig. 3 and Fig. 4 in the section above. Fig. 3 displays the digraph that indicates the relationships between different factors of safety program implementation. Factors are organized in a hierarchical system, in seven levels. Variables at the lower hierarchy level influence the upper level variables.

The findings of ISM reveal that Safety Training (ST) and Management Commitment (MC) have been found as the most prominent driving factors of safety implementation and rest at the high level of ISM model (Fig. 3). Similarly, in a study conducted by Abudayyeh et al., (2006), top management commitment including management support, teamwork Clear and realistic objectives is the most important factor in the implementation of safety programs. In fact, Management participates consistently in safety activities and assigns the necessary resources to safety, which is of equal importance to other construction parties. According to Fang and Wu (2013), management commitment is of utmost importance in establishing the safety strategy and in allocating resources to safety. In addition, from this study, the provision of safety training is another important factor to improve safety performance. Loosemore and Malouf (2019) considered safety training as one of the important driving factors for the safety program implementation. Safety training is defined by several indicators such as number of safety education days per year received by a safety officer and frequency of a foreman's reminding new workers of safety regulations. Formal safety training for new employees shall be given and specific training shall be provided on a regular basis periodically, if required.

Furthermore, it should be noted that communication factor (X2) positioned at the second-high level of the ISM hierarchy, reveals great influence for the implementation of construction safety program. Besides, we must note that the mid portion of the ISM hierarchy is occupied by seven factors namely Safety Rewards/Incentives (SRI), Safety Culture (SC), Staffing for Safety (SFS), Safety Plan (SP), Safety Knowledge and Skills (SKS), Pre-task Safety Measures (PSM) and Safety Resource (SR). These variables play an important role in connecting level 3 to level 6 . In the less significant segment of factors, there are two critical factors namely Operating Environment (OE) and Worker Involvement (WI). These two factors have high dependency power and they are based on the remaining variables of our proposed model. Workers involvement is important to prevent safety incidents in construction sites (Zwetsloot et al., 2017). Workers should acquire information about safety and have a good knowledge of best practices to reduce safety risks. The worker involvement factor can only be achieved when the other factors are carefully treated. Higher levels of motivation for safety can also be increased by the level of participation of workers in safety events. MICMAC research findings (Fig.4) complement the structure of the ISM hierarchy by specifying the driving power and also the dependency power of each variable. It is important to bring these findings together, as it will enable us to create and enforce actions and policies more effectively. We can observe that three variables namely Safety Training (ST), Management Commitment (MC) situated in the first level of ISM hierarchy (Fig.3) and have the highest driving force (Fig.4). Hence, the highest priority should be given to these two factors. This result supports the results of previous studies (Zamani et al., 2020; Loosemore and Malouf, 2019; Abudayyeh et al., 2006 and Huang et al., 2012), pointing out the critical role of training and management engagement in the implementation of construction safety programs. Regarding the effect of factor X3 (Safety Training), priority should be given to it as located at the first level and at the first highest driving power. As we can see in the FMSM (Table 10), Safety Training can apply direct influence on 10 factors namely X2, X4, X5, X6, X7, X9, X10, X11, X12 and X13. This implies that decision makers should give more importance to this factor (Safety Training). Fuzzy MICMAC analysis highlights Safety Culture (SC), 
communication (C), Staffing for Safety (SFS), Safety Plan (SP), Safety Knowledge and Skills (SKS) as the linkage factors. Such factors are the most significant, since they are reactive in nature and form a connection between system input factors and output factors. These variables are interrelated, and additional acts will influence the remaining factors as well as the whole system (Malek and Desai, 2019). We can see that these factors have several relations with numerous factors, but if these variables are not addressed correctly, they can produce some difficulties during the implementation of the security program. Then, it is suggested that greater attention should be paid to the development and the improvement of communication skills for construction workers and between workers and top management (He et al., 2019). Addressing the effect of Safety Plan (SP), an early-stage safety plan served as a basis for any effective safety program, including specific safety and health priorities reports, protocols and measures understood to ensure a safe working atmosphere (Bavafa et al., 2018). As shown in the FMSM (Table 10), Safety Plan can exert direct influence on seven factors. This means that its dispatch over the entire system is significant and proper attention to this factor would certainly improve efficiency and effectiveness of safety results.

Regarding the effect of safety culture (SC), we can see that this factor can exert direct influence on ten factors, as shown in the FMSM (Table 10). Generally, safety training (ST) which is defined as a driver factor may help developing employees' knowledge and competence to work safely and stimulate a positive safety culture in the company or in any project. Construction safety culture is seen as a combination of attitudes, opinions, principles, habits and standards shared in a building project team by individuals and groups from various parties (Fang and Wu, 2013). Moreover, from Fuzzy MICMAC analysis (Fig 4), it has been found that there are five dependent factors: Worker Involvement (WI), Pre-task Safety Measures (PSM), Operating Environment (OE), Safety Rewards/Incentives (SRI) and Safety Resource (SR). These five dependent barriers are affected by driving and link barriers. As suggested by Gan et al. (2018), dependent factors can be progressed if powerful variables are well discussed. For example, we can see that the performance of the dependent factor X10 (Worker Involvement) is largely determined by communication (x2), which is a linkage factor. Meanwhile, this factor is largely determined by safety training ( $\mathrm{x} 3$ ) which is considered as a driving factor. The company must be able to integrate such considerations as the first phase of planning to introduce an equitable safety program. The systematic understanding of the variables and their reciprocal relationships requires a thorough learning of the practical approach which encourages policymakers' identification of numerous pinholes in the implementation of the safety program.

\section{Conclusions and future researches}

The present research highlights the systematic analysis designed to recognize the relationship between construction safety program variables. Previous research did not use the combined ISM-Fuzzy MICMAC approach as the framework for defining the relationship between various factors affecting safety program implementation through a structural hierarchy model. By identifying the interrelationship between safety factors via ISM, we are able to explore new perspectives to lead to the implementation of the security program. Most studies based on ISM have only adopted MICMAC procedure to measure driving power and dependency, however the present research has implemented Fuzzy MICMAC analysis that improves the precision of effects.

The identification of factors as well as the measurement of driving and dependency power provide useful perceptions for implementing construction safety programs. The contextual relationships given for factors in this study enable decisionmakers to develop effective policies, guidelines, and regulations in order to achieve the most critical factors for successful safety program. The factors "safety training" and "management engagement" are one of the most significant factors. Many other variables with high power of control merit more consideration such as communication, Safety culture, Staffing for safety, Safety knowledge and skills and so on. The main limitation of this study is that the application is based on ISM technique which uses subjective input from the experts. First, as the model is developed by seeking the opinions of experts, so in nature it can be considered judgmental. Such limitations provide the path for future research, because statistical methods such as confirmatory factor analysis can reduce the bias in the opinion of experts. Second, Model is developed by reviewing the literature by considering 13 factors but it may not be the exhaustive list of factors. There may be also some other factors. In addition, the present proposed model can be confirmed by means of other approaches such as Systems Dynamic Modelling (SDM) and/or Structural Equation Modelling (SEM).

\section{References}

Abudayyeh, O., Fredericks, T. K., Butt, S. E., \& Shaar, A. (2006). An investigation of management's commitment to construction safety. International Journal of Project Management, 24(2), 167-174.

Aksorn, T., \& Hadikusumo, B. H. W. (2008). Critical success factors influencing safety program performance in Thai construction projects. Safety Science, 46(4), 709-727.

Al-Bsheish, M.A., bin Mustafa, M., \& Ismail, M.A. (2017). Enhancing safety performance by recognizing the role of perceived management commitment to safety in the Jordanian healthcare industry: Conceptual framework. International Journal of Business and Social Research, 7(1), 1-10.

Al-Humaidi, H. M., \& Tan, F. H. (2010). Construction Safety in Kuwait. Journal of Performance of Constructed Facilities, 24(1), 70-77.

Barbaranelli, C., Petitta, L., \& Probst, T. M. (2015). Does safety climate predict safety performance in Italy and the USA? Cross-cultural validation of a theoretical model of safety climate. Accident Analysis \& Prevention, 77, 35-44. 
Bavafa, A., Mahdiyar, A., \& Marsono, A. K. (2018). Identifying and assessing the critical factors for effective implementation of safety programs in construction projects. Safety Science, 106, 47-56.

Ben Mabrouk N. (2020). Analysis of Critical Factors Influencing the Supply Chain Performance of Small and Medium Enterprises. Journal of Advanced Manufacturing Systems, 19(4), 1-17.

Ben Mabrouk N. (2020a). Interpretive structural modeling of critical factors for buyer-supplier partnerships in supply chain management. Uncertain Supply Chain Management, 8(3), 613-626.

Ben Mabrouk, N., Ibrahim, S., \& Eddaly, M. (2021). Success factors of lean six sigma implementation in manufacturing. Uncertain Supply Chain Management, 9(1).

Ben Mabrouk, N. (2020). Green supplier selection using fuzzy Delphi method for developing sustainable supply chain. Decision Science Letters, 10(1), 63-70.

Brahm, F., \& Singer, M. (2013). Is more engaging safety training always better in reducing accidents? Evidence of selfselection from Chilean panel data. Journal of Safety Research, 47, 85-92.

Charehzehi, A. \& Ahankoob, A. (2012). Enhancement of safety performance at construction site. International Journal of Advances in Engineering \& Technology, 5(1), 303-312.

Cooper, M.D (2000). Towards a model of safety culture. Safety Science, 36, 111-136.

Faisal, M.N., Banwet, D.K., \& Shankar, R. (2006). Supply chain risk mitigation: Modeling the enablers. Business Process Management Journal, 12(4), 535-552.

Fang, D., \& Wu, H. (2013). Development of a Safety Culture Interaction (SCI) model for construction projects. Safety Science, 57, 138-149.

Fang, D.P., Huang, X.Y. \& Hinze, J. (2004). Benchmarking studies on construction safety management in China. Journal of Construction Engineering and Management, 130(3), 424-432.

Feng, Y. (2013). Effect of safety investments on safety performance of building projects. Safety Science, 59, $28-45$.

Flin, R., Mearns, K., O’Connor, P., \& Bryden, R. (2000). Measuring safety climate: identifying the common features. Safety Science, 34(1-3), 177-192.

Gan, X., Chang, R., Zuo, J., Wen, T., \& Zillante, G. (2018). Barriers to the transition towards off-site construction in China: An Interpretive structural modeling approach. Journal of Cleaner Production, 197, 8-18.

Gangwar, M. and Goodrum, P.M. (2005). The effect of time on safety incentive programs in the US construction industry. Construction Management and Economics, 23(8), 851-859.

Haadir, S. A., \& Panuwatwanich, K. (2011). Critical Success Factors for Safety Program Implementation among Construction Companies in Saudi Arabia. Procedia Engineering, 14, 148-155.

Hasan, A., \& Jha, K. N. (2013). Safety incentive and penalty provisions in Indian construction projects and their impact on safety performance. International Journal of Injury Control and Safety Promotion, 20(1), 3-12.

He, C., Jia, G., McCabe, B., Chen, Y., \& Sun, J. (2019). Impact of psychological capital on construction worker safety behavior: Communication competence as a mediator. Journal of Safety Research, 71, 231-241.

Hinze, J. \& Rabound, P. (1988). Safety on large building construction projects. Journal of Construction Engineering and Management, 114(2), 286-293.

Hinze, J. Hallowell, L., \& Baud, K. (2013). Construction safety best practices and relationships to safety performance. Journal of Construction Engineering and Management, 139(10), 04013006.

Huang, Y.-H., Verma, S. K., Chang, W.-R., Courtney, T. K., Lombardi, D. A., Brennan, M. J., \& Perry, M. J. (2012). Management commitment to safety vs. employee perceived safety training and association with future injury. Accident Analysis \& Prevention, 47, 94-101.

Ismail, Z., Doostdar, S \& Harun, Z. (2012). Factors influencing the implementation of a safety management system for construction sites. Safety science. 50(3), 418-423.

Jafari, M. J., Gharari, M., Kalantari, S., Omidi, L., Ghaffari, M., \& Fardi, G. R. A. (2015). The influence of safety training on improvement in safety climate in construction sites of a firm. Safety Promotion and Injury Prevention, 2(4), 257264.

Jain, V., \& Raj, T. (2015). Modeling and analysis of FMS flexibility factors by TISM and fuzzy MICMAC. International Journal of System Assurance Engineering and Management, 6(3), 350-371.

Jannadi, M. O. (1996). Factors affecting the safety of the construction industry. Building Research \& Information, 24(2), $108-112$.

Jayant, A., \& Azhar, M. (2014). Analysis of the Barriers for Implementing Green Supply Chain Management (GSCM) Practices: An Interpretive Structural Modeling (ISM) Approach. Procedia Engineering, 97, 2157-2166.

Jitwasinkul, B., \& Hadikusumo, B. H. W. (2011). Identification of Important Organisational Factors Influencing Safety Work Behaviours in Construction Projects. Journal of Civil Engineering and Management, 17(4), 520-528.

Kaswan, M. S., \& Rathi, R. (2019). Analysis and modeling the enablers of Green Lean Six Sigma implementation using Interpretive Structural Modeling. Journal of Cleaner Production, 231(10), 1182-1191.

Khan, K. M. I, Suguna, K.\& Raghunath, P.N. (2015). A study on safety management in construction projects. International Journal of Engineering Science and Innovative Technology, 4, 119-128.

Kumar, S., Gorane, S., \& Kant, R. (2015). Modelling the supplier selection process enablers using ISM and fuzzy MICMAC approach. Journal of Business \& Industrial Marketing, 30(5), 536-551.

Law, W. K., Chan, A. H. S., \& Pun, K. F. (2006). Prioritising the safety management elements: A hierarchical analysis for manufacturing enterprises. Industrial Management and Data Systems, 106(6), 778-792. 
Lee, S. \& Halpin, D.W. (2003). Predictive tool for estimating accident risk. Journal of Construction Engineering and Management, 129(4), 431-436.

Leveson, N. (2015). A systems approach to risk management through leading safety indicators. Reliability Engineering \& System Safety, 136, 17-34.

Li, C.-H., \& Li, H.-M. (2009). Developing a Model to Evaluate the Safety Management Performance of Construction Projects. International Conference on Management and Service Science. doi:10.1109/icmss.2009.5304613.

Li, R. Y. M., Chau, K. W., Lu, W., Ho, D. C. W., Shoaib, M., \& Meng, L. (2019). Construction hazard awareness and construction safety knowledge sharing epistemology. International Conference on Smart Infrastructure and Construction (ICSIC), Driving Data-Informed Decision-Making, Churchill College, Cambridge, UK, $283-290$.

Liu, Y., Zhang, Z., \& Mao, Z. (2020). Analysis of influencing factors in pre-evacuation time using Interpretive Structural Modeling. Safety Science, 128, 104785.

Loosemore, M., \& Malouf, N. (2019). Safety training and positive safety attitude formation in the Australian construction industry. Safety Science, 113, 233-243.

Majumdar, A., \& Sinha, S. K. (2018). Analyzing the barriers of green textile supply chain management in South-east Asia using interpretive structural modelling. Sustainable Production and Consumption, 17, 176-187.

Malek, J., \& Desai, T. N. (2019). Interpretive structural modelling based analysis of sustainable manufacturing enablers. Journal of Cleaner Production, 238, 117996.

Manu, P., Mahamadu, A. M., Ath, C., Heng, A. Y. T., \& Kit, S. C. (2017). Health and safety management practices of contractors in South East Asia: A multi country study of Cambodia, Vietnam, and Malaysia. Safety Science, 107, 188201.

Namian, M., Albert, A., Zuluaga, C. M., \& Behm, M. (2016). Role of safety training: Impact on hazard recognition and safety risk perception. Journal of Construction Engineering and Management, 142(12), 1-10.

Omran, A., Omran, A. \&. Kakir A. H. P. (2010). Critical success factors that influencing safety program performance in Malaysian construction projects case studies. Journal of Academic Research in Economics, 2(1), 124-134.

Pheng, L. S. \& Shiua, S. (2000). The maintenance of construction safety: riding on ISO 9000 quality management systems. Journal of Quality in Maintenance Engineering, 6(1), 28-44.

Qureshi, M. N., Kumar, D., \& Kumar, P. (2008). An integrated model to identify and classify the key criteria and their role in the assessment of 3PL services providers. Asia Pacific Journal of Marketing and Logistics, 20(2), $227-249$.

Sawacha, E., Naoum, S. \& Fong, D. (1999). Factors affecting safety performance on construction sites. International Journal of Project Management, 17(5), 309-315.

Shakerian, M., Jahangiri, M., Alimohammadlou, M., Nami, M., \& Choobineh, A. (2019). Individual cognitive factors affecting unsafe acts among Iranian industrial workers: An integrative meta-synthesis interpretive structural modeling (ISM) approach. Safety Science, 120, 89-98.

Suraji, A., Duff, A. R., \& Peckitt, S. J. (2001). Development of Causal Model of Construction Accident Causation. Journal of Construction Engineering and Management, 127(4), 337-344.

Tam, C. M., Zeng, S. X., \& Deng, Z. M. (2004). Identifying elements of poor construction safety management in China. Safety Science, 42(7), 569-586.

Teo, E. A. L., Ling, F. Y. Y., \& Chong, A. F. W. (2005). Framework for project managers to manage construction safety. International Journal of Project Management, 23(4), 329-341.

Thakkar, J., Kanda, A., \& Deshmukh, S. G. (2007). Evaluation of buyer-supplier relationships using an integrated mathematical approach of interpretive structural modeling (ISM) and graph theoretic matrix. Journal of Manufacturing Technology Management, 19(1), 92-124.

Wanberg, J., Harper, C., Hallowell, M. R., \& Rajendran, S. (2013). Relationship between Construction Safety and Quality Performance. Journal of Construction Engineering and Management, 139(10), 04013003.

Warfield, J. N. (1974). Developing Subsystem Matrices in Structural Modeling. IEEE Transactions on Systems, Man, and Cybernetics, $S M C-4(1), 74-80$.

Yiu, N. S. N, \& Chan, D. W. M. (2018). Project characteristics indicating safety performance. International Journal of Engineering \& Technology, 7(3.29), 110-114.

Zamani, V., Banihashemi, S. Y., \& Abbasi, A. (2020). How can communication networks among excavator crew members in construction projects affect the relationship between safety climate and safety outcomes? Safety Science, 128, 104737.

Zhang, S., Boukamp, F., \& Teizer, J. (2015). Ontology-based semantic modeling of construction safety knowledge: Towards automated safety planning for job hazard analysis (JHA). Automation in Construction, 52, $29-41$.

Zwetsloot, G. I. J. M., Kines, P., Ruotsala, R., Drupsteen, L., Merivirta, M.-L., \& Bezemer, R. A. (2017). The importance of commitment, communication, culture and learning for the implementation of the Zero Accident Vision in 27 companies in Europe. Safety Science, 96, 22-32.

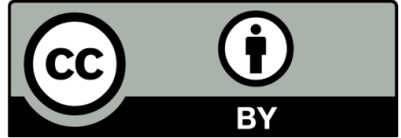

(C) 2021 by the authors; licensee Growing Science, Canada. This is an open access article distributed under the terms and conditions of the Creative Commons Attribution (CC-BY) license (http://creativecommons.org/licenses/by/4.0/). 